\title{
Experimental Investigations on the Strut Controlled Thrust Vectoring of a Supersonic Nozzle
}

\author{
T. Thillaikumar, P. Bhale and M. Kaushik ${ }^{\dagger}$ \\ Department of Aerospace Engineering, Indian Institute of Technology, Kharagpur - 721302, India \\ †Corresponding Author Email: mkaushik@aero.iitkgp.ac.in
}

(Received October 19, 2019; Accepted January 11, 2020)

\begin{abstract}
The attitude control of a rocket engine using the control surfaces becomes cumbersome particularly in larger rockets with high payload. In such cases, a more effective means of producing forces for controlling the flight is the deflection of exhaust gases, referred to as the gas-dynamic steering or the thrust vector control. In this study, the effect of a strut on the exhaust gas deflection, deployed at the locations; $0.62 \mathrm{~L}, 0.72 \mathrm{~L}$ and $0.8 \mathrm{~L}$ in the divergent-portion of a Mach 1.84 nozzle at over-expanded, correctly-expanded and under-expanded states of the jet, has been experimentally investigated. The level of expansion at the nozzle exit is varied by changing the settling chamber pressures from 4 bar to 8 bar, in steps of 2 bar. Further, to study the effect of aspect ratio, the height of strut is varied as $1.5 \mathrm{~mm}, 2.5 \mathrm{~mm}$ and $3.5 \mathrm{~mm}$. The strut of height $3.5 \mathrm{~mm}$, deployed at $\mathrm{x} / \mathrm{L}=0.72$, is found to be the most effective thrust vector control at overexpanded conditions; with a maximum jet deflection of about $3.6^{\circ}$, obtained at a settling chamber pressure of 4 bar. The Schlieren flow visualization images confirm the findings of wall static pressure data.
\end{abstract}

Keywords: Thrust vectoring, Strut, Mach number, Wall static pressure, Schlieren technique.

\section{NOMENCLATURE}

\author{
An nozzle cross sectional area \\ $\mathrm{A}_{\mathrm{s}}$ projected area of strut \\ $\mathrm{F}$ resultant vector \\ $\mathrm{F}_{\mathrm{x}} \quad$ thrust force \\ $\mathrm{F}_{\mathrm{y}} \quad$ control force direction \\ $h$ strut height
}

\section{INTRODUCTION}

Gas-dynamic steering, commonly known as thrust vector control (TVC) is a technique, used to manipulate the direction of the thrust, which eventually controls the attitude of the vehicle. This technique has received a great attention since long due to its practical application in developing the control systems for attitude adjustment and performing the maneuvers. Thrust vectoring can be accomplished using either the mechanical or the fluid systems. A mechanical system such as a moving pintle, used for changing the throat area of a convergent-divergent nozzle, requires a drivemechanism (Sung et al. 2017; Lee et al. 2013). There are other more effective mechanical mechanisms which include the use of vanes or tubular nozzle extensions (compression deflection) or the use of beveled-exit nozzles (expansion deflection), though

\author{
L nozzle length \\ $\mathrm{M}_{\mathrm{o}} \quad$ freestream Mach number \\ $\mathrm{P} \quad$ wall static pressure \\ $\mathrm{P}_{\mathrm{o}} \quad$ stagnation pressure \\ $\theta \quad$ jet defection angle
}

these require some change from conventional nozzle designs and increase the manufacturing complexity (Abdullatif and El-Sharkawy 1977). The throat area can also be modified by introducing a secondary flow in the direction perpendicular to the primary flow, resulting in interactions between the two flows (Sung and Heo 2012; Yagle et al. 2001). It is found that this flow configuration exhibits high reliability and requires no drive-mechanism; however, it also needs a large storage tank to store sufficient quantity of fluid for injection into the primary flow. Clearly, the injection of an auxiliary fluid flow, acting as the thrust vector control, makes the system heavier and less attractive for longer endurance. Therefore, to overcome these difficulties, a small solid body (or strut) is inserted into the primary flow, as depicted in Fig. 1. The effect of struts in supersonic flows is examined in a number of studies both numerically and experimentally (Hsu et al. 2009; 


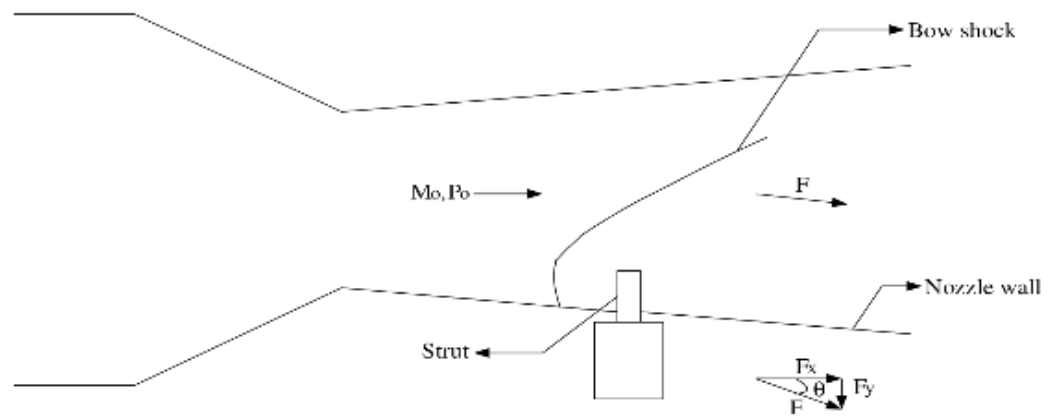

Fig. 1. Schematic diagram of the thrust vector control using strut.

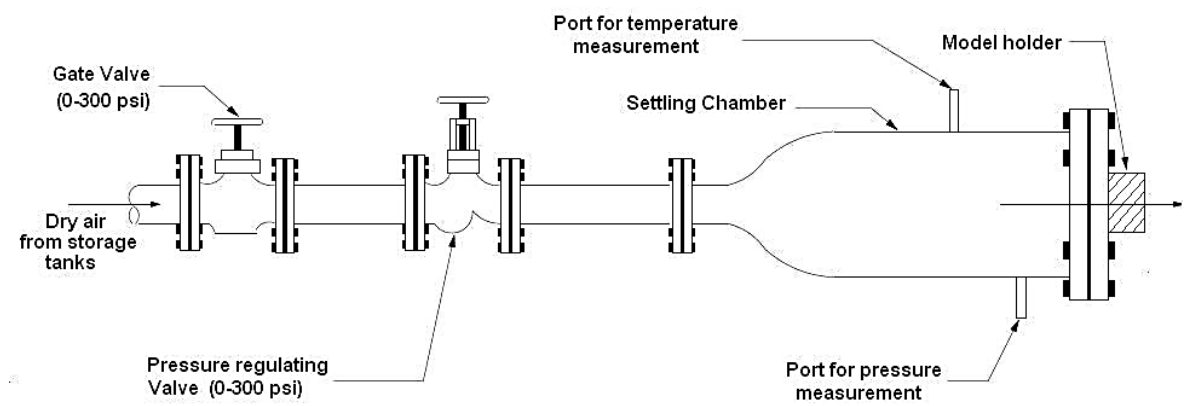

Fig. 2. Schematic diagram of the free jet-test setup.

Zhang et al. 2015; and Song et al. 2016). However, all these studies essentially have focused on the mixing enhancement characteristics of the supersonic jets and there are relatively fewer studies which examine the effect of struts on the thrust vector controls (Hsu et al. 2009; Zhang et al. 2015; Song et al. 2016; Talda and Franke 1989; Kaushik and Rathakrishnan 2013; Kaushik and Rathakrishnan 2015). But it should be noted that a strut deployed in the convergent-divergent nozzle controls the thrust vector in the same way as the injected fluid in the transverse direction. In addition, the mechanism involving strut thrust vector control (STVC) is geometrically simple, light weight and relatively cheaper than the fluid injection system.

Therefore, in the present study the thrust vectoring capability of a strut, deployed at $\mathrm{x} / \mathrm{L}=0.62,0.72$ and 0.81 in the divergent portion of a convergentdivergent nozzle, has been experimentally investigated. To quantify the thrust vectoring capability, the static pressures for both uncontrolled and controlled nozzles were measured at the wall mounted ports. Besides, the waves prevailing in the uncontrolled and controlled configurations have been visualized using the Schlieren technique.

\section{EXPERIMENTAL METHODOLOGY}

In the present study, the experiments were conducted in the jet-test facility available at the Madras Institute of Technology, Chennai, India. The test facility consists of an air supply system (which consists of compressor and storage tanks) and an open jet test facility. Figure 2 shows a schematic sketch of the free jet test experimental facility.

The compressed air from the storage tank was supplied continuously to the settling chamber through a control valve. The nozzle inlet pressures were set and maintained constant using the pressure regulating valves (PRVs). The study was performed at the over-expansion, correct-expansion and underexpansion states of the nozzle by varying the settling chamber pressures as 4 bar, 6 bar and 8 bar, respectively. The throat and exit areas of the nozzle were $113.09 \mathrm{~mm}^{2}$ and $167.41 \mathrm{~mm}^{2}$, respectively (Fig. 3 ). The semi-divergence angle of the convergentdivergent nozzle was 1.517 degrees. The area-ratio of the nozzle was 1.48 with corresponding exit Mach number as 1.84 . The convergent-divergent nozzle and struts were made of stainless steel. To study the influence of strut on thrust vector control, three different locations and heights $(1.5 \mathrm{~mm}, 2.5 \mathrm{~mm}$ and $3.5 \mathrm{~mm}$ ) were chosen, so that we can find the effective location and height of strut for better control efficiency. It should be noted that the strut locations of $x / L=0.62, x / L=0.72$ and $x / L=0.81$ represents the $1 / 3^{\text {rd }}, 1 / 2^{\text {nd }}$ and $2 / 3^{\text {rd }}$ distance of divergent portion length from nozzle throat, respectively. Here, the strut located near downstream of throat $(x / L=0.62)$, where there is a chance of shock impingement on upper wall. Even though, the strut generated vortices provides higher mixing enhancement in the downstream direction. The strut 


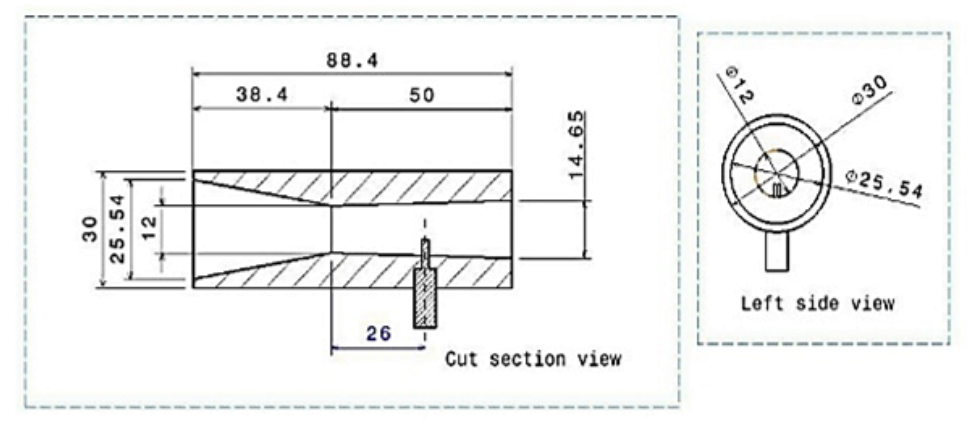

All dimensions are in mm

Fig. 3. Schematic diagram of the Mach 1.84 nozzle, with the strut deployment in divergent-portion.

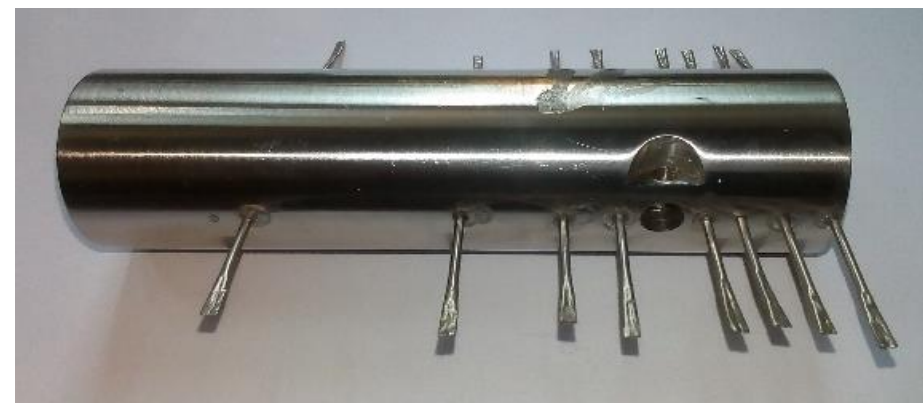

Fig. 4. Photograph of the fabricated nozzle with wall pressure ports for strut position at $0.72 \mathrm{~L}$.

positioned at near nozzle exit $(\mathrm{x} / \mathrm{L}=0.81)$ on divergent portion, where limited possibility of shock impingement on upper wall. However, strut location too much downstream from throat will result in reverse flow on nozzle exit, which reduces the performance of thrust vector control. Further, the optimized benefits of limited shock impingement and higher mixing enhancement can be obtained with insertion of strut at the mid-section $(\mathrm{x} / \mathrm{L}=0.72)$ on divergent portion. These struts were deployed at the locations; $\mathrm{x} / \mathrm{L}=0.62,0.72$ and 0.81 in the divergentsection of the convergent-divergent nozzle. To investigate the effect of aspect ratio, three different heights; $1.5 \mathrm{~mm}, 2.5 \mathrm{~mm}$ and $3.5 \mathrm{~mm}$ of triangularshaped struts were used, so that the strut protruding well above the boundary layer to cause pressure rise.

The geometric blockage offered by a strut in divergent portion of the nozzle is calculated using Eq. (1).

Geometric blockage $(\%)=\left(\frac{A_{s}}{A_{n}}\right) \times 100$

where, $A_{s}$ denotes the projected area of strut and $A_{n}$ denotes the nozzle cross-sectional area.

Table 1 Geometric Blockage for different heights of the strut, deployed at different $x / L$ locations

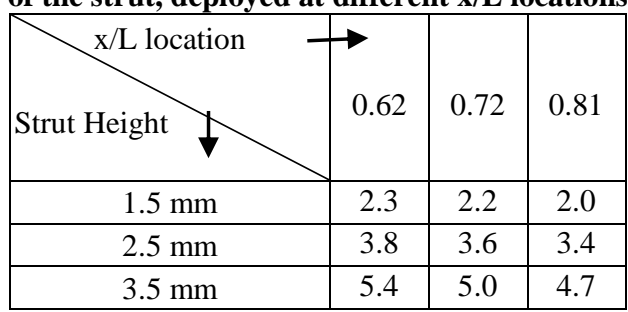

The geometric blockage (in percentage) offered by the struts of different heights and at different $\mathrm{x} / \mathrm{L}$ locations in the divergent-section of the convergentdivergent nozzle is tabulated in Table 1.

Note that, a greater geometric blockage causes a higher thrust loss and thus to keep the losses to a minimum, the blockage offered by all the struts is maintained below 5\% (Kaushik. 2012). The static pressures were measured at different ports mounted along the nozzle wall, as seen in Fig. 4.

These pressure ports were connected to a 16-channel intelligent pressure scanner (Fig. 5) of model number PSI 9116, having a measuring range up to $17 \mathrm{bar}$. The user-friendly software provided by the manufacturer has been used to interface the pressure scanner with a computer that acquired the data and displays the reading from all the 16 channels, simultaneously on the monitor. The pressure measurement was performed with a precision of $\pm 0.1 \%$. The jet structure and shock pattern in the jet field were visualized using the Schlieren technique.

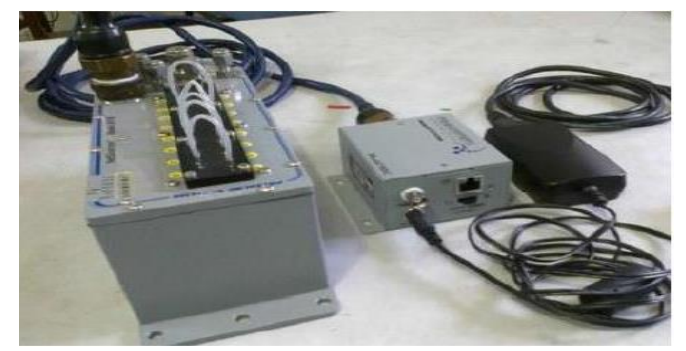

Fig. 5. Digital pressure scanner. 


\section{RESULTS AND DISCUSSION}

\subsection{Wall Static Pressure Variation}

To quantify the thrust vector control efficiency of strut, the variation of wall static pressure was plotted against the axial distance. The wall static pressure (p) was made non-dimensional with the stagnation pressure $\left(\mathrm{p}_{0}\right)$ and the axial distance was made nondimensional with the nozzle length (L). The effects of deployment location for varying height of struts on wall static pressure variation at different operating conditions are discussed in the following sections.

\section{a. For Strut Deployed at $x / L=0.62$}

The non-dimensional static pressure $\left(\mathrm{p} / \mathrm{p}_{0}\right)$ variation for the lower and upper surfaces of the nozzles, at varying heights of the strut located at $x / L=0.62$, are shown in Figs. 6, 7 and 8. Figure 6a, depicts the wall static pressure distribution over the lower surface of the supersonic nozzle operating at overexpanded conditions. It can be seen that the flow starts accelerating soon after entering the convergentsection, attains the choking at the throat and further accelerates in the divergent-section, for both uncontrolled and strut-controlled nozzles. Here, the nozzle throat location is $\mathrm{x}=0.43 \mathrm{~L}$. When the strut is penetrated, the nozzle divergent portion $(x=0.62 \mathrm{~L})$, strong bow shock is generated and a separation bubble occurs. The upstream influence of the separation bubble block the nozzle section and reduces the area in the upstream region of the strut, which eventually leads to the increment in Mach number for strut controlled nozzles (wall pressure port at $x=0.36 \mathrm{~L}$ ). As moving further downstream, it is observed from Fig. 6a, that for all the strutcontrolled nozzles the static pressure at the lower surface is found to be higher than the uncontrolled nozzle. Also, the static pressure upstream of the strut increases with increase of the strut height. This could be due to the formation of a strong bow-shock ahead of the strut. In contrast, the static pressure $($ at $\mathrm{x} / \mathrm{L}=$ 0.64 ) is found to be decreasing behind the struts; with $3.5 \mathrm{~mm}$ strut showing a maximum decrease. This is because of the suction effect created by the trailing edge vortices shed from the strut. Further, up to $\mathrm{x} / \mathrm{L}$ $=0.9$, an accelerating trend in static pressure increase is observed for all the nozzle configurations and in the far-field, the pressure finally approaches the freestream value. Likewise, the lower surface, a similar trend in wall static pressure variation on the upper surface is also observed (Fig. 6b). Here, the strut generated bow shock extends up to the nozzle upper wall.

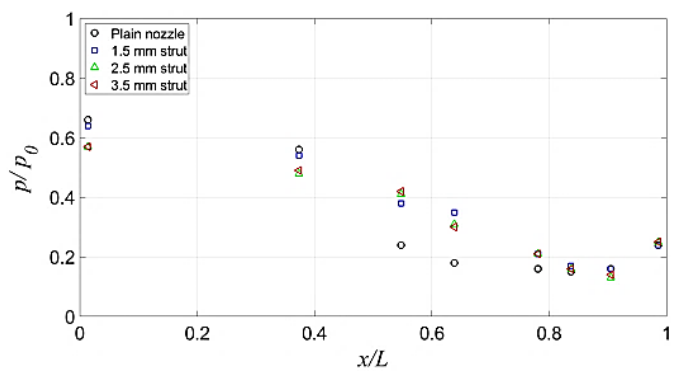

(a)

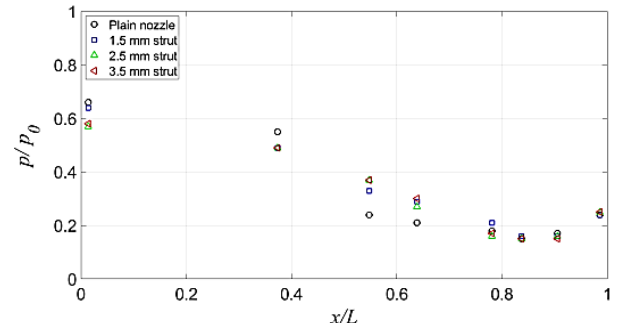

(b)

Fig. 6. Wall static pressure variation for (a) lower surface, (b) upper surface (overexpanded).

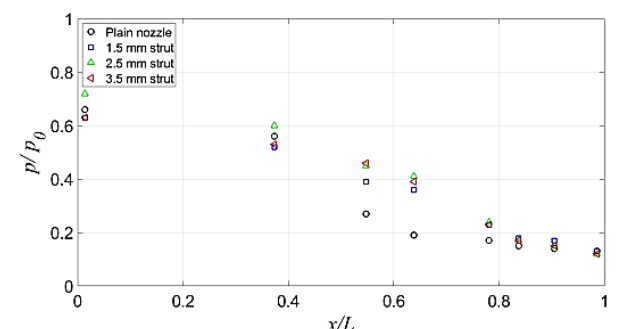

(a)

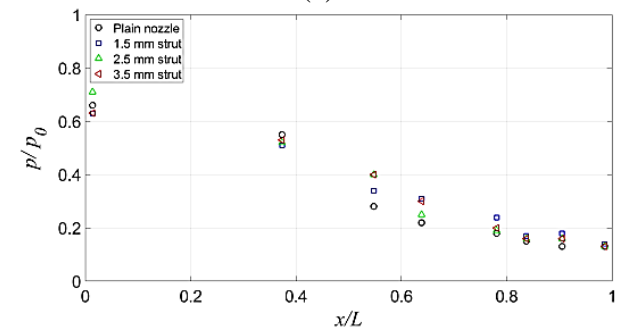

(b)

Fig. 7. Wall static pressure variation for (a) lower surface, (b) upper surface (correctly-expanded).

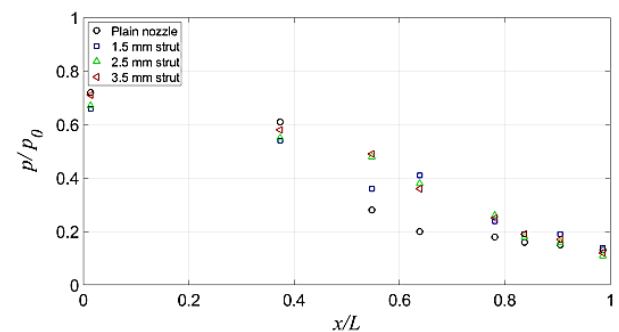

(a)

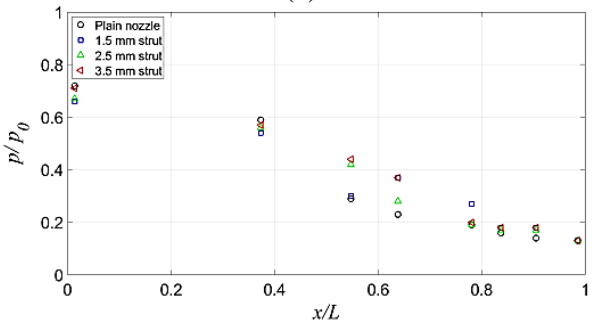

(b)

Fig. 8. Wall static pressure variation for (a) lower surface, (b) upper surface (underexpanded).

For the correctly-expanded conditions, the wall static pressure distribution over the lower surface of the supersonic nozzle, is shown in Fig. 7a. It is easily observable that, both $2.5 \mathrm{~mm}$ and $3.5 \mathrm{~mm}$ struts cause a moderate rise in the wall static 
pressure, whereas, $1.5 \mathrm{~mm}$ strut leads to a considerable rise in the pressure. Downstream of the strut location, the rise in static pressure first accelerates and then it approaches to the ambient pressure at the nozzle exit. However, in this case the shortest strut shows the highest pressure rise on the upper surface as compared to the longer struts (Fig. 7b).

The static pressure variation over the lower surface of supersonic nozzle, operating at under-expanded conditions, is given in Fig. 8a. Because of the bowshock formation, a higher static pressure in the immediate downstream $(\mathrm{x} / \mathrm{L}=0.64)$ of the $1.5 \mathrm{~mm}$ strut is observed. Further, the static pressure distribution at the lower surface of the nozzle is shown in Fig. 8b. Here, the nozzle controlled with $2.5 \mathrm{~mm}$ strut shows the lowest pressure rise at the axial location of $0.64 \mathrm{x} / \mathrm{L}$.

\section{b. For Strut Deployed at $\mathrm{x} / \mathrm{L}=\mathbf{0 . 7 2}$}

For strut location at $\mathrm{x} / \mathrm{L}=0.72$, the non-dimensional static pressure $\left(\mathrm{p} / \mathrm{p}_{0}\right)$ variation for the lower and upper surfaces of the nozzles are shown in Figs. 9, 10 and 11. Figure 9a shows the wall static pressure distribution over the lower surface of the supersonic nozzle operating at overexpanded conditions. At $\mathrm{x} / \mathrm{L}$ $=0.64$, the static pressure falls below the ambient pressure, which produces a local suction effect. However, at the subsequent port location $(\mathrm{x} / \mathrm{L}=$ 0.78 ), a significant rise in static pressure, particularly for the struts of heights $2.5 \mathrm{~mm}$ and $3.5 \mathrm{~mm}$, is observed. This may be because of the fact that when a strut is introduced in the divergent portion of the nozzle, it produces a strong bow-shock which eventually increases the static pressure downstream. Impingement of bow-shock on the nozzle wall essentially leads to the boundary layer detachment. In addition, with increase of strut height a rise in static pressure was observed in all cases. At the farthest port location corresponding to $0.84 \mathrm{~L}$, an initial drop in static pressure is seen which subsequently rises to freestream value for both the struts of heights $2.5 \mathrm{~mm}$ and $3.5 \mathrm{~mm}$. This gradual rise in pressure indicates the reattachment of the flow to the wall. Here, an insignificant rise in the pressure due to $1.5 \mathrm{~mm}$ strut indicates the generation of a relatively weaker shock.

The wall static pressure variation at the upper surface of supersonic nozzle under overexpanded conditions is shown in Fig. 9b. For both uncontrolled and controlled configurations, the flow is found to be accelerating up to $\mathrm{x} / \mathrm{L}=0.78$; with a rapid increase in static pressure for the strut of height $3.5 \mathrm{~mm}$. This is again because of the boundary layer detachment caused by the bow-shock generated at the strut and extends till the upper surface of the nozzle. In far field, the pressure gradually rises to freestream value for all the nozzle configurations.

Similar behavior in wall pressure distribution was observed for both correctly-expanded and underexpanded nozzles. At the lower surface of supersonic nozzle, a rapid increase in static pressure was found at $\mathrm{x} / \mathrm{L}=0.78$ for both $2.5 \mathrm{~mm}$ and $3.5 \mathrm{~mm}$ strut cases, which is shown in Figs. 10a and 11a. Thereafter the flow accelerates towards the nozzle exit $(x / L=0.98)$, where the same value of static pressure was observed for both correctly-expanded and under-expanded nozzles, as shown in Figs. 10b and 11b. Thus, it is clearly evident that a supersonic nozzle operating at over-expanded conditions and controlled with a strut experiences a large jet deflection.

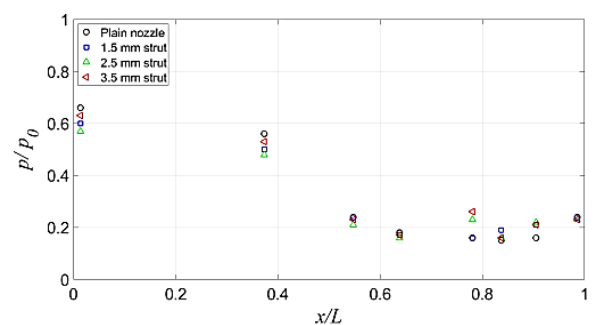

(a)

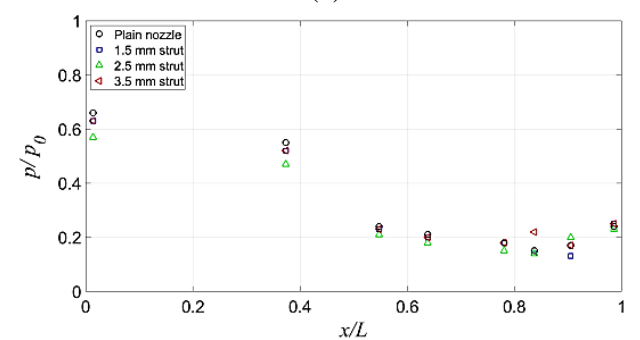

(b)

Fig. 9. Wall static pressure variation for (a) lower surface, (b) upper surface (overexpanded).

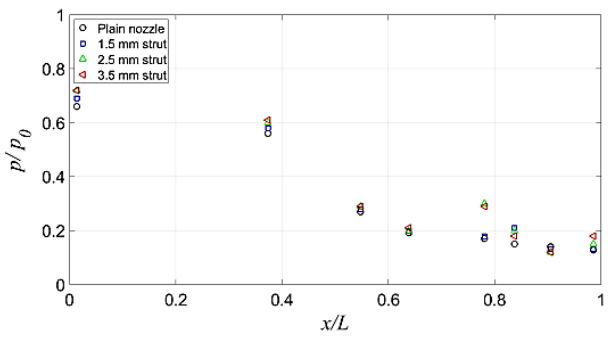

(a)

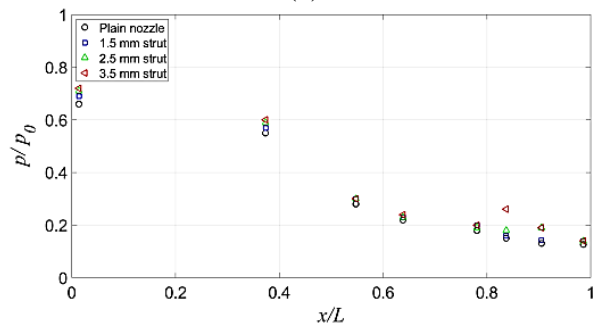

(b)

Fig. 10. Wall static pressure variation for (a) lower surface, (b) upper surface (correctlyexpanded).

\section{c. For Strut Deployed at $\mathrm{x} / \mathrm{L}=\mathbf{0 . 8 1}$}

For the strut deployed at $\mathrm{x} / \mathrm{L}=0.81$, the static pressure variations at the lower and upper walls of the uncontrolled and controlled nozzles are given in Figs 12, 13 and 14. Figure 12a, depicts the static pressure distribution over the lower surface of an over-expanded nozzle. Up to $\mathrm{x} / \mathrm{L}=0.78$, a rapid flow acceleration (accompanied with a sudden drop of static pressure) is observed. However, beyond this 
location, the pressure rises again for all the controlled configurations, which is due to the reattachment of boundary layer as well as the shock wave. The rise in static pressure increases with the height of strut (Fig. 12b). This reveals that the shock wave, generated by the longer struts, extends up to the upper wall of the nozzle.

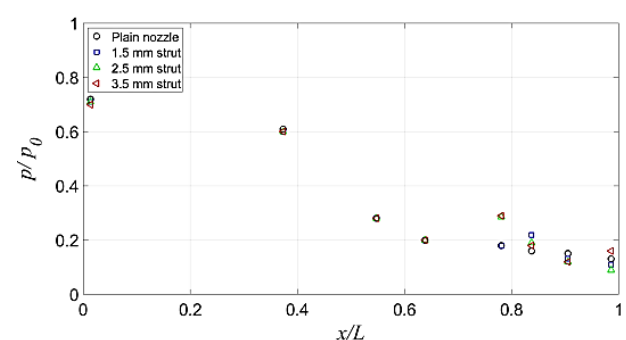

(a)

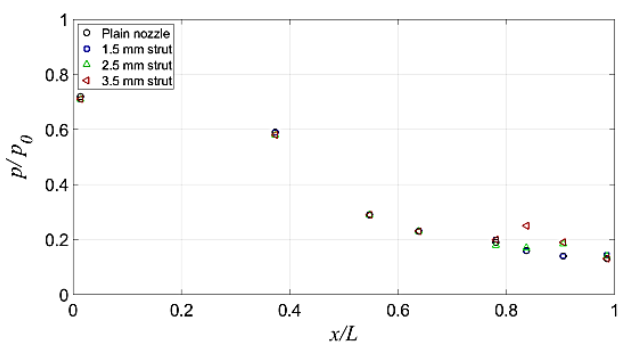

(b)

Fig. 11. Wall static pressure variation for (a) lower surface, (b) upper surface (underexpanded).

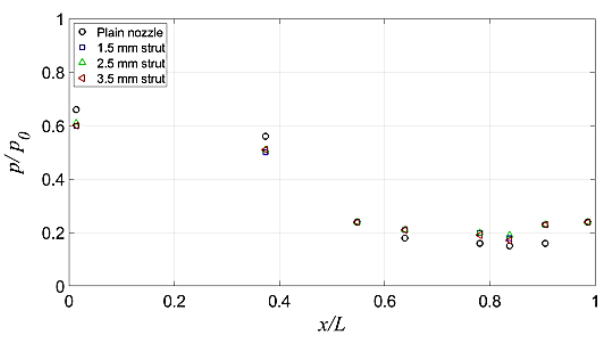

(a)

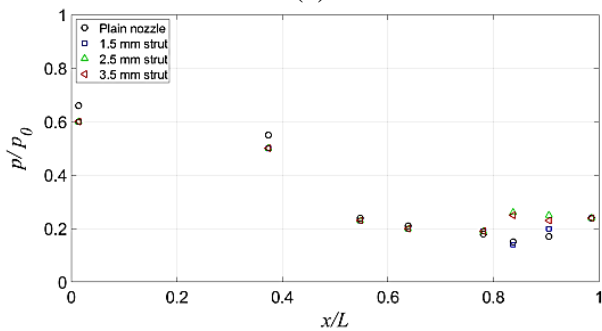

(b)

Fig. 12. Wall static pressure variation for (a) lower surface, (b) upper surface (overexpanded).

Figure 13a, depicts the wall static pressure distribution over the lower surface of the supersonic nozzle, operating at correctly-expanded conditions. At $x / L=0.9$, a considerable rise in the static pressure is observed for the strut-controlled configurations. The nozzle upper surface is affected by the insertion of a strut as the bow-shock, generated upstream, impacts on the opposite wall. This effect is more pronounced in the case of longer struts. Hence, a significant pressure rise is seen for both $2.5 \mathrm{~mm}$ and $3.5 \mathrm{~mm}$ struts (Fig. 13b).

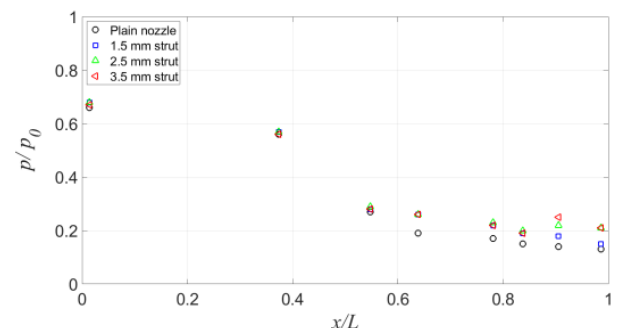

(a)

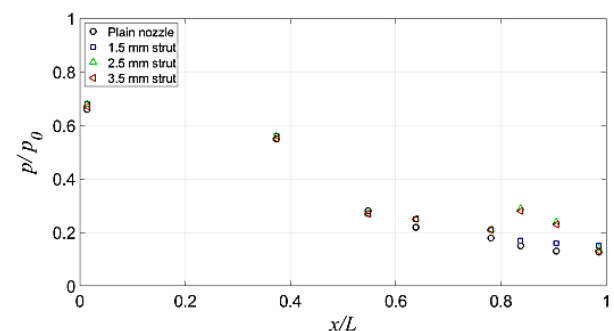

(b)

Fig. 13. Wall static pressure variation for (a) lower surface, (b) upper surface (correctlyexpanded).

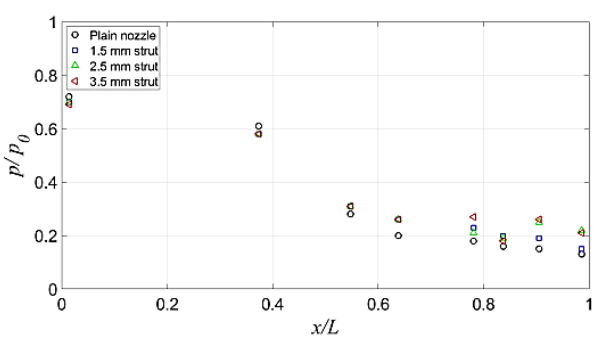

(a)

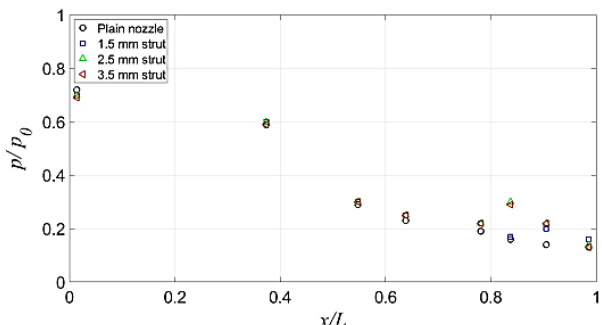

(b)

Fig. 14. Wall static pressure variation for (a) lower surface, (b) upper surface (underexpanded).

For the uncontrolled and controlled nozzles, operating at under-expanded conditions, the pressure variations over the lower surface are shown in Fig. 14a. The longest strut $(3.5 \mathrm{~mm})$ causes a significant increase in the static pressure at the wall-mounted port location of $x / L=0.78$. This is due to the formation of a stronger bow-shock, which propagates further upstream and impinges upon the lower wall of the nozzle. 
For the upper surface also, a similar pressure characteristics is obtained, as seen in 14b. Here, both the longer struts $(2.5 \mathrm{~mm}$ and $3.5 \mathrm{~mm})$ cause a significant increase in the static pressure, measured at the port configured at $\mathrm{x} / \mathrm{L}=0.84$. This is in contrast to the result of $1.5 \mathrm{~mm}$ strut-controlled configuration where only a marginal increase in pressure is observed. Clearly, the bow-shock generated at the shortest strut is relatively weak and not extendable up to the upper surface.

\subsection{Schlieren flow Visualization}

The waves prevailing in the uncontrolled and controlled nozzle flow fields were visualized with Schlieren optical flow visualization technique.

\section{a. For Strut Deployed at $\mathrm{x} / \mathrm{L}=\mathbf{0 . 6 2}$}

The visualization images for the over-expanded state of the Mach 1.84 nozzles with strut location at $\mathrm{x} / \mathrm{L}$ $=0.62$ are shown in Fig. 15. At over-expansion, the nozzle exit pressure is less than the ambient pressure and thus, an oblique shock formation at the nozzle exit can be observed in Fig. 15a. This oblique shock increases the nozzle exit pressure to the ambient pressure. Further, the left-running and right-running oblique shocks cross each other at the jet centerline and get reflected from the jet boundary as the expansion waves. These expansion waves again cross each other and get reflected from the outer jet boundary as compression waves. This process continues and leads to the formation of a periodic shock-cell structure in the jet. When a strut is introduced in the nozzle (at $\mathrm{x} / \mathrm{L}=0.62$ ), the shock cell structures get altered as seen in Figs. 15b, 15c and $15 \mathrm{~d}$. Also, the spacing between shock-cells as well as the supersonic core length reduces considerably.

For correctly-expanded jet, the flow visualization images for uncontrolled and controlled nozzles with strut at $\mathrm{x} / \mathrm{L}=0.62$ are shown in Fig. 16. The Schlieren image for uncontrolled nozzle operating at correct-expansion is shown in Fig. 16a. Even though the flow is correctly-expanded (i.e., the nozzle exit pressure is equal to the backpressure), the flow has to turn away from the nozzle axis to occupy the free space available. This essentially leads to the formation of expansion waves at the nozzle exit. Nevertheless, the strength of expansion waves in correctly-expanded flow is much less than in the under-expanded flow (Kaushik. 2012). Further, for the controlled nozzles the number of shock-cell structures are found to be lower than the plain nozzle (Figs. 16b, 16c and 16d). However, no jet deflection is observed in these cases.

For an under-expanded jet, the nozzle exit pressure is higher than the ambient pressure and hence the expansion-wave forms at nozzle exit, which can be seen in Fig. 17. Thus, both correctly-expanded and under-expanded flows encounter the formation of expansion waves at the nozzle exit. These waves cross each other at the jet centerline and get reflected from the jet boundary as compression waves. These compression waves again cross each other at the jet axis and get reflected as expansion waves. This process continues and generates a periodic shockcell structure, as shown in Fig. 17a. Even though the shock structures are modified due to the insertion of struts, no appreciable jet deflection is observed in these cases.

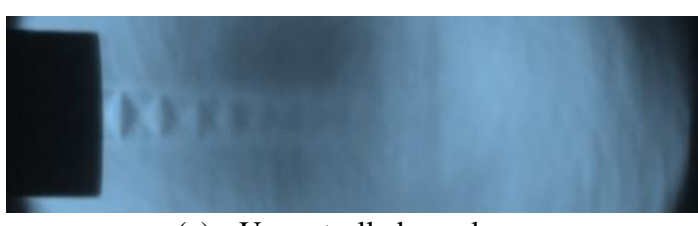

(a) Uncontrolled nozzle

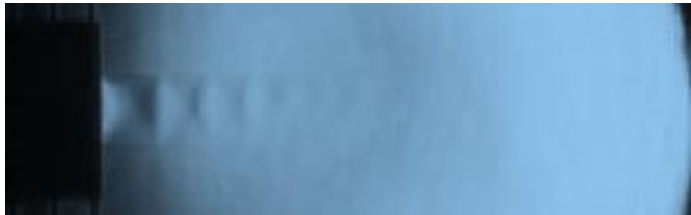

(b) Nozzle controlled with $1.5 \mathrm{~mm}$ strut

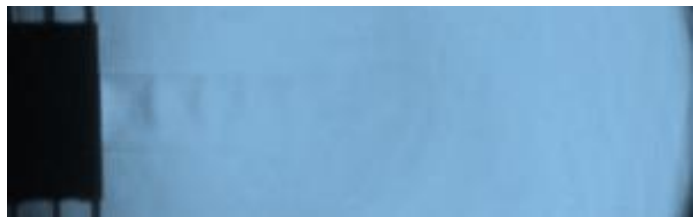

(c) Nozzle controlled with $2.5 \mathrm{~mm}$ strut

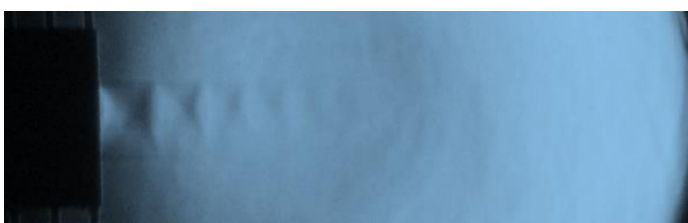

(d) Nozzle controlled with $3.5 \mathrm{~mm}$ strut

Fig. 15. Schlieren images of the uncontrolled and controlled nozzles (overexpanded).

\section{b. For Strut Deployed at $\mathrm{x} / \mathrm{L}=\mathbf{0 . 7 2}$}

For the struts, deployed at $0.72 \mathrm{~L}$, the visualization pictures for the Mach 1.84 nozzle, operating at overexpanded conditions, are shown in Fig. 18. When a strut is introduced, the jet is deflected downward for all the nozzles, as seen in Figs. 18a, 18b and 18c. This can be explained as follows; For the strut location $\mathrm{x} / \mathrm{L}$ $=0.72$, it can be noted in the Fig. 9 that the immediate downstream of strut, the high pressure and low pressure was observed on the lower wall and upper wall, respectively. However, in the downstream direction accelerating flow behavior observed on the lower wall due to the strut generated vortices. Whereas, high pressure region was observed on upper surface, which results in deflection of primary jet in downward direction. The jet deflection angle for 1.5 $\mathrm{mm}$ and $2.5 \mathrm{~mm}$ struts were estimated as $3.3^{\circ}$ and $3.5^{\circ}$, respectively. However, a maximum jet deflection angle of $3.6^{\circ}$ is observed for the $3.5 \mathrm{~mm}$ strut. The jet deflection angles for different strut lengths are tabulated in Table 2.

Table 2 Jet deflection angles for different heights of the strut, deployed in an overexpanded nozzle

\begin{tabular}{|c|c|c|}
\hline S. No & Strut Height & Deflection Angle \\
\hline 1 & $1.5 \mathrm{~mm}$ & $3.3^{\circ}$ \\
\hline 2 & $2.5 \mathrm{~mm}$ & $3.5^{\circ}$ \\
\hline 3 & $3.5 \mathrm{~mm}$ & $3.6^{\circ}$ \\
\hline
\end{tabular}




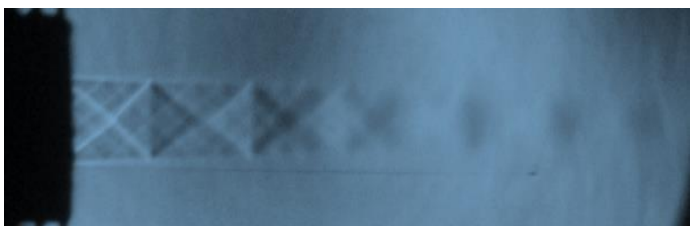

(a) Uncontrolled nozzle

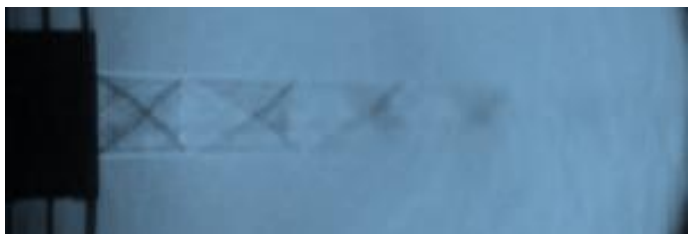

(b) Nozzle controlled with $1.5 \mathrm{~mm}$ strut

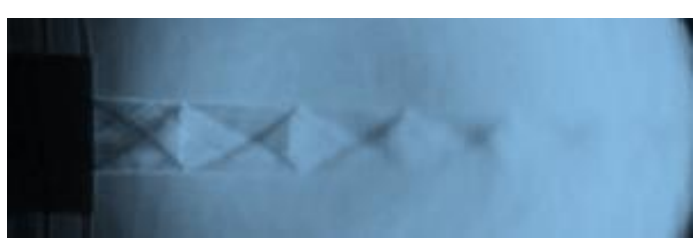

(c) Nozzle controlled with $2.5 \mathrm{~mm}$ strut

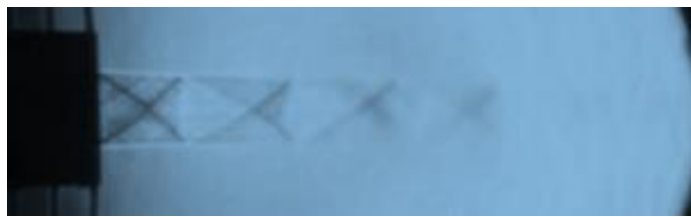

(d) Nozzle controlled with $3.5 \mathrm{~mm}$ strut

Fig. 16. Schlieren images of the uncontrolled and strut-controlled nozzles (correctly-expanded).

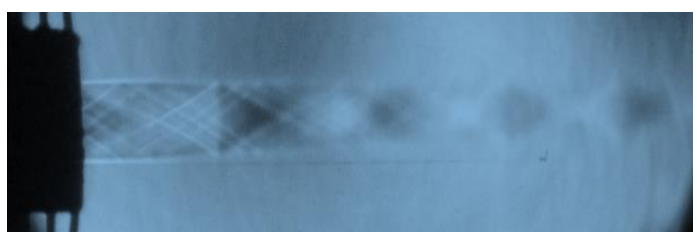

(a) Uncontrolled nozzle

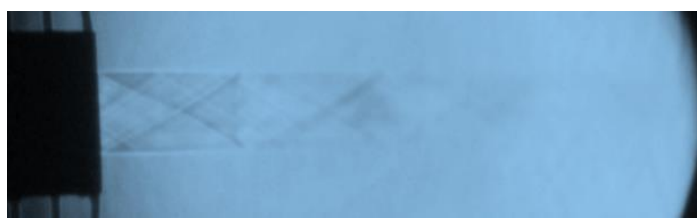

(b) Nozzle controlled with $1.5 \mathrm{~mm}$ strut

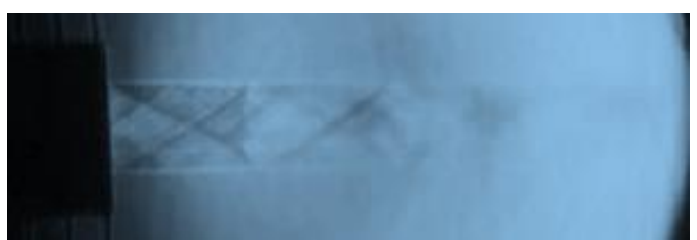

(c) Nozzle controlled with $2.5 \mathrm{~mm}$ strut

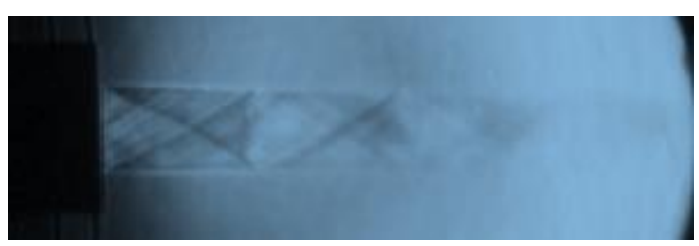

(d) Nozzle controlled with $3.5 \mathrm{~mm}$ strut

Fig. 17. Schlieren images of the uncontrolled and controlled nozzles (underexpanded).

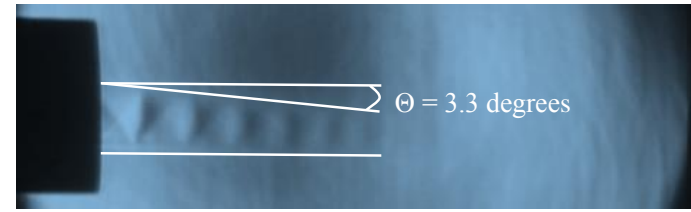

(a) Nozzle controlled with $1.5 \mathrm{~mm}$ strut

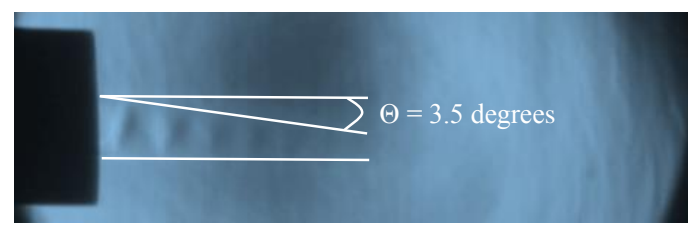

(b) Nozzle controlled with $2.5 \mathrm{~mm}$ strut

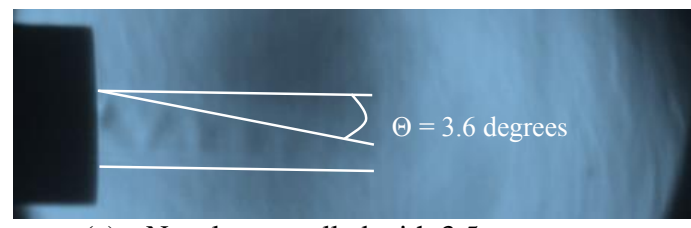

(c) Nozzle controlled with $3.5 \mathrm{~mm}$ strut

Fig. 18. Schlieren images of the controlled nozzles (overexpanded).

The Schlieren images for the correctly-expanded state of Mach 1.84 nozzle controlled with a strut (x/L $=0.72$ ), are shown in Fig. 19. Notice the generation of various shock waves from the upper wall of the nozzle, which are indeed due to the reflection of strut generated shock waves from the upper wall.

The visualization pictures for an under-expanded Mach 1.84 jet are shown in Fig. 20. The modification of shock-cells in the presence of struts can be clearly seen in Figs. 20a, 20b and 20c. The number of shockcells in the supersonic core are also reduced as compared to plain (uncontrolled) nozzle. Likewise, the previous location, the controlled nozzles once again experience no appreciable deflection of jet.

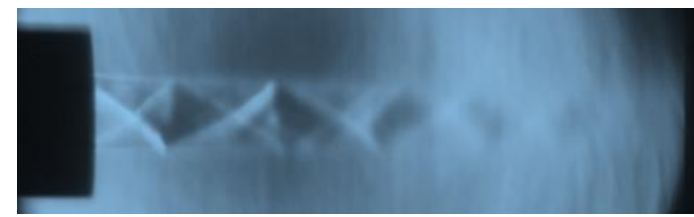

(a) Nozzle controlled with $1.5 \mathrm{~mm}$ strut

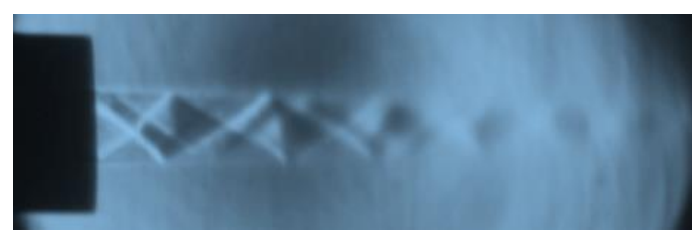

(b) Nozzle controlled with $2.5 \mathrm{~mm}$ strut

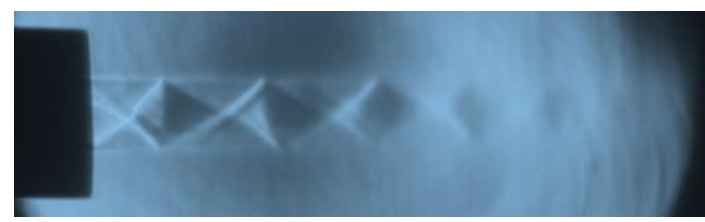

(c) Nozzle controlled with $3.5 \mathrm{~mm}$ strut

Fig. 19. Schlieren images of the controlled nozzles (correctly-expanded). 


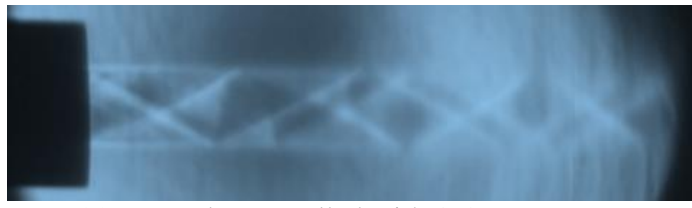

(a) Nozzle controlled with $1.5 \mathrm{~mm}$ strut

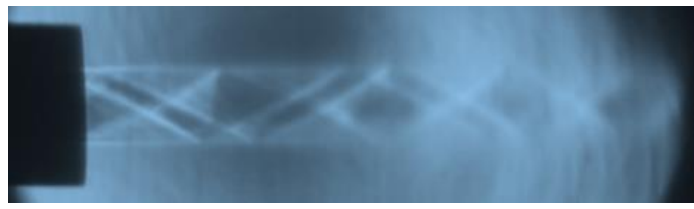

(b) Nozzle controlled with $2.5 \mathrm{~mm}$ strut

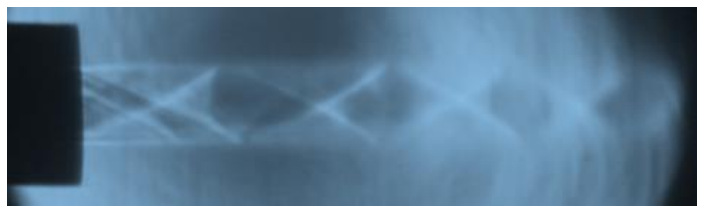

(c) Nozzle controlled with $3.5 \mathrm{~mm}$ strut

Fig. 20. Schlieren images of the controlled nozzles (underexpanded).

\section{c. For Strut Deployed at $\mathrm{x} / \mathrm{L}=0.81$}

For the farthest downstream location of the strut deployment corresponding to $0.81 \mathrm{~L}$, the visualization pictures are given in Fig. 21. The shock-cells are greatly modified in the presence of strut but the deflection observed in the jet is once again negligibly small.

The flow visualization images for the nozzle operating at correct-expansion are shown in Fig. 22. With the introduction of a strut, great alterations in the shock cell structures are achieved, which eventually results in the small diamond like structures (Figs. 22a, 22b and 22c).

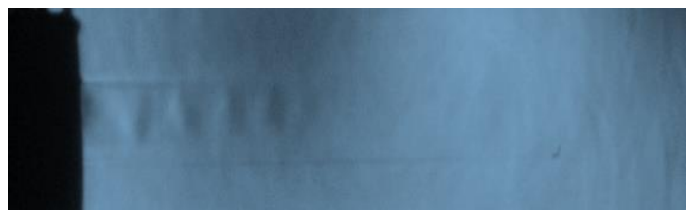

(a) Nozzle controlled with $1.5 \mathrm{~mm}$ strut

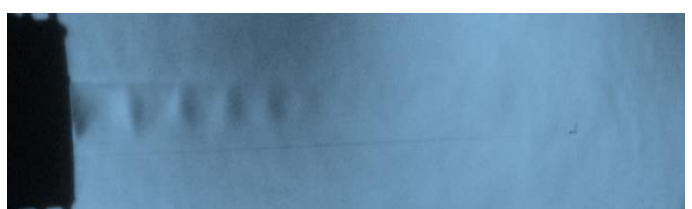

(b) Nozzle controlled with $2.5 \mathrm{~mm}$ strut

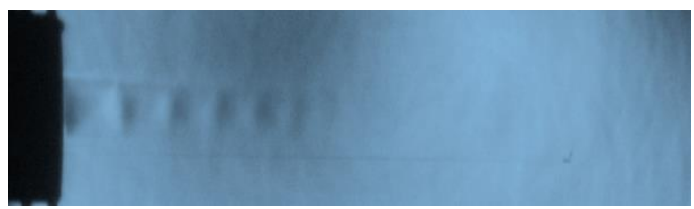

(c) Nozzle controlled with $3.5 \mathrm{~mm}$ strut

Fig. 21. Schlieren images of the controlled nozzles (overexpanded).

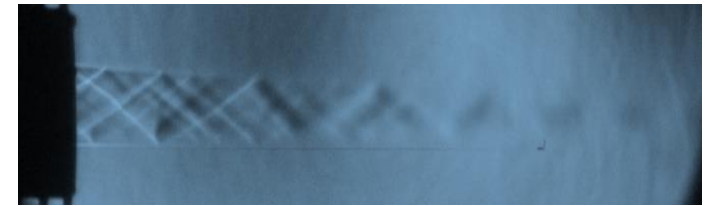

(a) Nozzle controlled with $1.5 \mathrm{~mm}$ strut

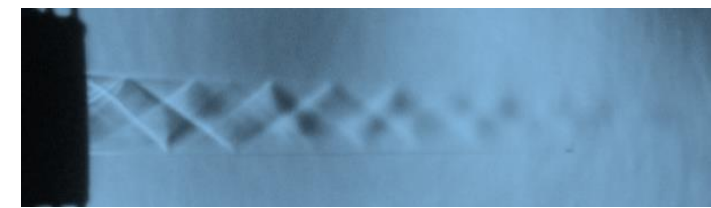

(b) Nozzle controlled with $2.5 \mathrm{~mm}$ strut

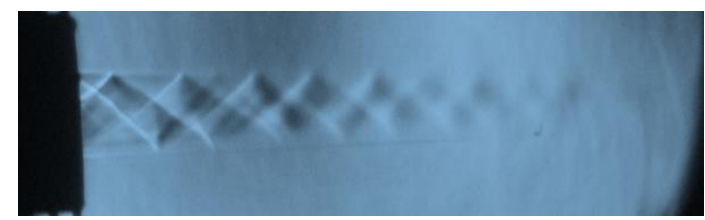

(c) Nozzle controlled with $3.5 \mathrm{~mm}$ strut

Fig. 22. Schlieren images of the controlled nozzles (correctly-expanded).

For an under-expanded nozzle, the Schlieren views are shown in Fig. 23. In all the controlled configurations, the first few shock-cells are more prominent, and they possess waves of considerable strengths. The subsequent cells however are less prominent, which clearly reveal an enhanced mixing of the jet with the ambient fluid.

Thus, it can be said that the deployment of a strut in the divergent-portion of a supersonic nozzle, operating at under-expanded conditions, has no significant effect on thrust vectoring. However, their deployment causes an enhanced jet mixing which, in turn, helps improve the aero-acoustic performance of a supersonic jet.

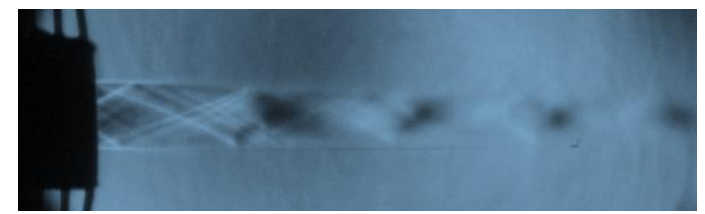

(a) Nozzle controlled with $1.5 \mathrm{~mm}$ strut

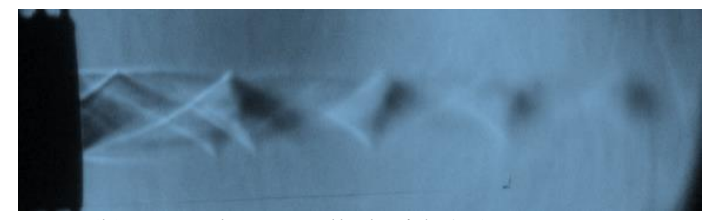

(b) Nozzle controlled with $2.5 \mathrm{~mm}$ strut

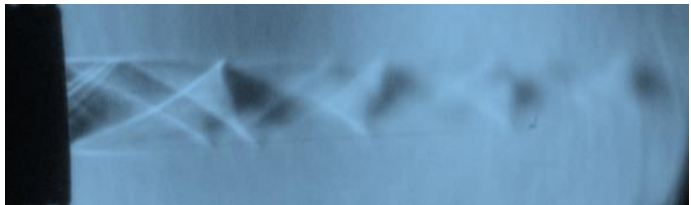

(c) Nozzle controlled with $3.5 \mathrm{~mm}$ strut

Fig. 23. Schlieren images of the controlled nozzles (underexpanded). 


\section{CONCLUSIONS}

In this study, the thrust vector controllability of a strut, deployed in the divergent-portion of a Mach 1.84 nozzle, is experimentally investigated. In the divergent-section, the strut was placed at three different locations; $\mathrm{x} / \mathrm{L}=0.62,0.72$ and 0.81 . At each location, struts of three different heights; 1.5 $\mathrm{mm}, 2.5 \mathrm{~mm}$ and $3.5 \mathrm{~mm}$ were investigated. The strut is found to be more effective in deflecting the jet flow field, especially in the presence of an adverse pressure gradient prevailing at the nozzle exit. A maximum jet deflection of about $3.6^{\circ}$ is achieved with $3.5 \mathrm{~mm}$ strut, deployed at the mid-section $(\mathrm{x} / \mathrm{L}$ $=0.72$ ) of the divergent-portion. The superior performance of the longest strut is due to the generation of a stronger bow-shock, which eventually increases the pressure imbalance at the nozzle exit and leads to a larger jet deflection. The qualitative analysis of the Schlieren images supports the findings of the wall pressure data.

\section{ACKNOWLEDGEMENTS}

The authors deeply acknowledge the Madras Institute of Technology, Chennai, India for providing the supersonic jet-test facility to carry out the experiments.

\section{REFERENCES}

Abdullatif, T. and El-Sharkawy (1977). Experimental Studies on Thrust Vector Control in Solid Propellant Rockets. 13th Propulsion Conference, AIAA, Orlando, FL, U.S.A.

Hsu, K., C. Carter, M. Gruber and C. Tam (2009). Mixing Study of Strut Injectors in Supersonic Flows. 45th AIAA/ASME/SAE/ASEE Joint Propulsion Conference and Exhibit, Denver, Colorado.

Kaushik, M. (2012). Innovative Passive Control Techniques for Supersonic Jet Mixing. First Edition, Germany: Lambert Academic
Publishing.

Kaushik, M. and E. Rathakrishnan (2013) Corrugated limiting tab for jet mixing. International Journal of Turbo and Jet Engines 30, 359-73.

Kaushik, M. and E. Rathakrishnan (2015). Tab Aspect Ratio Effect on Supersonic Jet Mixing. International Journal of Turbo and Jet Engines $32,265-273$.

Lee, J., B. Park and W. Yoon (2013). Parametric Investigation of the Pintle Perturbed Conical Nozzle Flows. Aerospace Science and Technology 26, 268-279.

Song, W., D. Zhang and D. Shi (2016). Numerical Study of Combinations of Strut and Cavity in a Round Supersonic Combustor. International Journal of Turbo and Jet-Engines 36, 219-231.

Sung, H. and J. Heo (2012). Fluidic Thrust Vector Control of Supersonic Jet Using Co-flow Injection. Journal of Propulsion and Power 28, 858-861.

Sung, H., K. Jeong and J. Heo (2017). Performance characteristics of a pintle nozzle using the conformal sliding mesh technique. Aerospace Science and Technology 61, 85-94.

Talda, T. and M. Franke, (1989). Two-dimensional confined jet thrust vector control. 25th Joint Propulsion Conference, AIAA, Monterey, CA.

Yagle, P. J., D. N. Miller, K. B. Ginn and J. W. Hamstra (2001). Demonstration of Fluidic Throat Skewing for Thrust Vectoring in Structurally Fixed Nozzles. Journal of Engineering for Gas Turbines and Power 123, 502-507.

Zhang, C., J. Chang, W. Shi and W. Bao (2015). Influence factor analysis of performance parameter for a strut/cavity supersonic combustor. 51st AIAA/ASME/SAE/ASEE Joint Propulsion Conference and Exhibit, Orlando, FL. 